\title{
Liquid Lines: Synthesizing Perception and Precision
}

\author{
JEN MAIGRET \& MARÍA ARQUERO DE ALARCÓN \\ University of Michigan
}

For the designer, imagination travels in the line. Lines can redraw the present, defy conventions, recast new orders and shape the future. Lines establish territorial boundaries, communicate written language and construction intentions yet lines are also fluid. When experienced in the world, lines can be ephemeral and dynamic and inspire a methodological interplay between perception and precision.

In this regard, lines are liquid. Conversely, when liquid is represented through the act of drawing lines, a similarly incomplete view is formed. It is within these gaps between time and matter or certainty and precision, that lines can reveal opportunities for design. By slipping into a mindset that crosses, tests, traces and inhabits lines, then the limits of what is "in" or "out" and "here" versus "there" melt away. Instead, this paper positions an attitude toward design that revels in contingency and speculates on the temporal and material qualities that make architecture a thriving component of the dynamic, built environment. To illustrate these ambitions, this paper revisits the lost disciplinary legacy of the term disegno and explores contemporary ideas emerging from the consideration of "atmosphere" in the formulation of architectural ideas. Three projects illustrate this proposition and draw "liquid lines" to produce conditions of "both and" by practicing expanded perception and dynamic precision.

\section{INTRODUCTION}

"In a wave or cloud, these leading lines show the run of the tide and of the wind, and the sort of change which the water or vapour is at any moment enduring in its form, as it meets shore, or counter-wave, or melting sunshine. (...) Try always, whenever you look at a form, to see the lines in it which have had power over its past fate and will have power over its futurity ... see that you seize on those, whatever else you miss." 1

-Ruskin, The Elements of Drawing

The contemporary condition of ubiquitous technology access and streaming data has changed the way we experience and imagine our physical world. Complexity, central to the consideration and study of dynamic systems, is an elusive condition to perceive without the aid of visual expressions of data. Contrast this with Ruskin's 1909 edition of The Elements of Drawing. Unconcerned with the quantification of the world, he sets forth a qualitative method to "learn drawing that you may be able to set down clearly, and usefully, records of such things as cannot be described in words." Following this premise, students are guided through meticulously described exercises that, eventually, open their eyes to the power to observe, and capture, such elements as the "leading lines" in waves and clouds.

This paper posits that these two paradigms of perception and precision, today, are neither antithetical nor mutually exclusive to one another. Instead, the design of the constructed environment is one of the most powerful interfaces between large-scale, complex systems and the perception and embodiment of environmental ephemera. In particular, this paper explores two themes of disciplinary interest (1) the contemporary examination of the relevance of weather and atmosphere as a medium to embrace uncertainty within the realm of science and, (2) the reflection on the etymology and evolution of the term "disegno" as a frame of theoretical reference.

The broader aims are twofold: first, a close ex amination of environmental perception of dynamic systems (atmosphere) paired with design precision (drawing) to advance the articulation of projects motivated by and explored through the platform of an interdisciplinary design studio. Second, the concerns and interests set forth in this paper reach beyond any specific design instance and participate in disciplinary debates of contemporary attitudes toward "context" and environmental stewardship. 


\section{LIQUID}

"Climate is what on an average we may expect; weather is what we actually get." 2

\section{-Andrew John Herbertson, Outlines of Physiography}

Jonathan Hill's (2012) Weather Architecture, one example of a number of recent publications dealing with issues of atmosphere in architecture, is a compelling call for the practice of "immaterial architecture." Weather is a central protagonist to his argument and is employed to illustrate a range of ways that the perceptual capacity of architecture might expand from singularly solid and stable toward a state of simultaneity - both solid and stable and immaterial and porous.

Beyond the realm of weather and climate, Hill's broader argument points toward a historic drift that has brought us to a disciplinary imbalance-where precision is unambiguously favored over uncertainty. "On a more fundamental note, immaterial architecture may revel in qualities - the subjective, unpredictable, porous and ephemeral-that are contrary to the solid, objective and respectable practice expected of a professional." 3

Similarly, the bias that perception and precision are mutually exclusive is laid bare in Lorraine Daston's and Peter Galison's writing about scientific desires to describe entropic natural forces. ${ }^{4,5}$ While the publication of their 2007 book, Objectivity, has been undoubtedly influential on the emerging discourse on atmosphere in the discipline of architecture, it has not gone without criticism. Central to one line of criticism is the book's emphasis on epistemology, to the exclusion of a broader consideration of methodologies, particularly those of scientific illustration. In a 2014 essay titled "Made Real: Artifice and Accuracy in Nineteenth-Century Scientific Illustration," Boris Jardine unpacks the contradictions negotiated when tools of illustration are deployed to precisely describe atmospheric conditions, such as the example of meteorologist Luke Howard's sketches (Figure 1) depicting and classifying clouds. ${ }^{6}$ "The emphasis on self-recording devices and the morals of machinery, important as it is, tends to focus our attention away from the often messy and convoluted means of image reproduction [...] that often involve steps that seem sharply at odds with narratives of increasing standardization and scientific restraint." 7

The question of how to quantifiably illustrate something as fleeting and dynamic as a cloud is one of the paper's central provocations that bears implications beyond this specific dilemma of representation. The author offers an alternate term for consideration as one piece of this larger puzzle. Rather than veiling unresolved conflicts emerging from the nineteenth century's study and ordering of natural systems as "mechanically objective," Jardine offers an alternative term, 'manufactured.' While "mechanical objectivity" suggests that the tools of depiction are inherently neutral and effectively separate scientific quantification from qualitative bias, "manufactured" acknowledges a feedback loop between the tools and the illustrator. In this case, the scientist is negotiating the imperfections of any given tool of representation and its ability to precisely, visually define scientific phenomena. In so doing, we might acknowledge inherent gaps between desired versus achieved precision toward a more

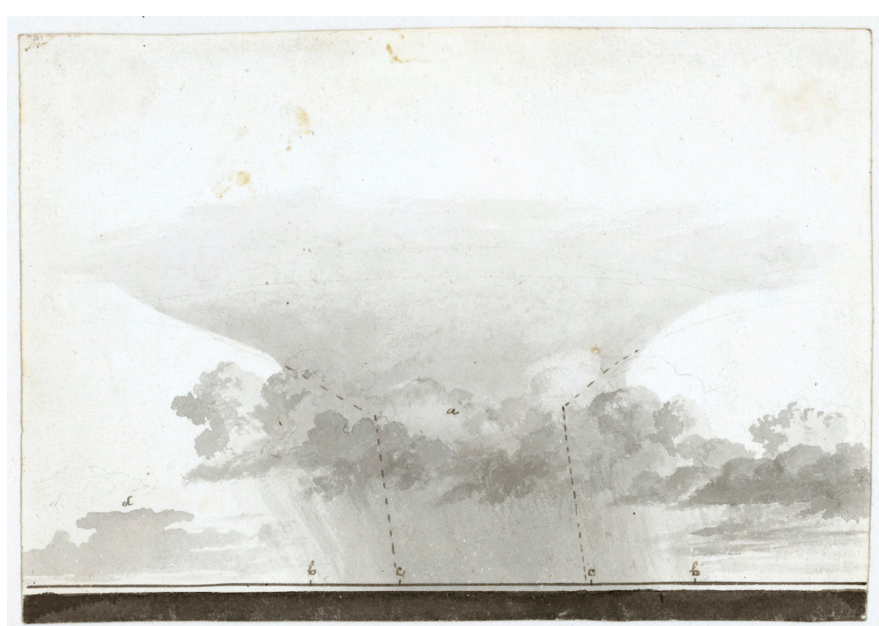

Figure 1: As a case study, Dr. Jardine closely analyses meteorologist Luke Howard's cloud sketches, which date from the beginning of the nineteenth century and accompany his novel classification scheme-the cirrus, stratus, and cumulus of modern weather watching. ${ }^{8}$

self-reflexive and therefore generative role for representation and visual translation.

\section{LINES}

"An active line on a walk, moving freely without a goal. A walk for walk's sake." 9

\section{-Paul Klee, Pedagogical Sketchbook}

The "drift" that Hill identifies favors scientific inquiry over all other forms of knowledge. However, the "inevitability" of this drift is a misunderstanding, akin to mistaking processes of evolution as directional or intentional. Rather, by re-examining the historic circumstances that bore influence on the present expression of the discipline of architecture, we suspend engrained practices and enrich the way we imagine possible futures. While the weather-- and by extension, atmosphere-continue to play important roles as loci of novel design generation in the discipline of architecture, this paper returns to Hill's earlier concept of "immaterial architecture" to expand themes, approaches and protagonists that also answer the call to "be flexible and open to conflicting perceptions and opinions," and "focus attention on the capacity to perceive one perceiving" thus, encouraging critical awareness of the spaces we inhabit. ${ }^{10}$

To illustrate this point, consider the etymology and evolution of meaning of the term "disegno." Originating in the Latin designo - to militarily mark out a territory-- the Italian form disegno rose to influence during the Renaissance and grew to encompass a breadth of meanings "from design, to drawing, plan, intention and even conspiracy." ${ }^{11}$ It was during this time that the liberation of the intellectual from the manual labor of building first elevated telos (construing) above techne (constructing). And, as an extension, knowing through your senses (perception) became divorced from knowing through your mind (intellect). While the loss of ambiguity and capacity in the concept of disegno was not an intentional act, it underwent a 
similar drift to Hill's observations about scientific epistemology. In contemporary writing, the use of the concept of disegno fluctuates between nostalgia for the craft of hand drawings to a "straw man" standing in for the failures in architectural education as examined in Reyner Banham's 1990 article, "Black Box: The Secret Profession of Architecture."

In Banham's words, "Architecture's master discipline, design, is simply disegno... (drawing is) a kind of meta-pattern that subsumes all other patterns (in architecture) and shelters them from rational scrutiny.. (the linked practice of design through drawing) has such crucial value for architects that being unable to think without drawing becomes the mark of one truly socialized into the profession of architecture." 12

Such a contemporary "narrowing" of the nuance in meanings of disegno produces a bottleneck that chokes the breadth of disciplinary inquiry preceding the present moment. Scholarship, including the work of Marta Ajmar, has revisited the historical context from which the term disegno emerged in order to expand its contemporary definition and recover the relevance of that lost knowledge for contemporary discourse. In particular, her work acknowledges the overwhelming influence that obsessions with classification played in parsing, categorizing and in establishing hierarchical orders in the "minor arts", including painting, sculpture and architecture. ${ }^{13} \mathrm{~A}$ practice that ultimately contributed to "the profound dichotomy between design and execution, between thinking and doing (...)" and, therefore, contributed to the loss of haptic (feeling) knowledge.

Furthermore, Ajmar problematizes the dominant rhetoric of Renaissance art theory's co-opting of "disegno" to promote a differentiation of the intellectual, and by association moral, status of the arts at the time and offers a more integrated approach to recuperate the possibility of attaining "interconnectedness between mind, body, materials and the environment which they inhabit." Similarly, this paper presents an expansive approach to design that fosters a reciprocal relationship between material and intellectual influences. In this way, the pursuit of Hill's "immaterial" or Ajmar's "manufactured" distill methods and feedback loops synthesizing construing with constructing, perception with intellect, and global with local.

\section{LIQUID LINES}

Liquid Lines, therefore, favors a "both and" approach to both address precision and embrace uncertainty. To do so, the liquid nature of lines are employed to engage a dynamic, "form-generating" design process that is not a "neutral" record of apriori, intellectualized ideas. Rather, each project contributes to the larger practice of integrated approaches to design, expressing the interconnectedness between intellect, action and materials. To illustrate these ambitions, the paper presents excerpts from three projects and provides glimpses into an ongoing calibration of design practice and expanded disciplinary methods.

\section{UNFOLDED SHORELINE}

Unfolded Shoreline (Figure 3) is an indexed representation that draws together the forces from land and water that influence issues of water quality throughout the Great Lakes Basin. Within the realm of water, uncertainty governs the ebb and flow of rainstorms, rivers and shorelines. Within the realm of terra firma, certainty is strongly preferred and bears systems of logic intended to bring order and stasis. The desire for certainty and stasis is strong enough to persuade us to anchor the shore to a line thereby yielding a more precisely describable and measurable shoreline. If, however, we observe shores without an expectation to locate a single line, then we no longer need to eliminate non-linear observations.

Furthermore, challenging the false notion that land and water meet in a single line offers an opportunity to explore the agency of design as a platform for conceptualization, imagination and interpretation. In this way, the drawing serves as an active space of probabilistic derivation. And, operates within the etymological realm of the verb "design" wherein, through its Latin and Greek roots, a productive tension between precision and incompleteness is negotiated in service of that which is elusive. ${ }^{14}$

By extension, if the default characteristics of "the cartographic" tend toward the illustrative and measured, then "mapping" the unfolded shoreline is, at its core, a projective exercise. ${ }^{16}$ The process of data selection, diagraming and synthesis define the ambition to abstract data and teach us to see differently. Specifically, "unfolding" serves as a technique for the spatial reorganization of representational and cartographic expectations. The shift from a latitudinal and longitudinal coordinate based space to that of a relational "line" assisted in a visual transformation from seeing things as familiar to seeing the shore"line" anew. This ultimately played a formative role shaping a series of projects addressing questions surrounding the interplay between urban watersheds, water quality and the impact of revitalized public spaces of cultural and ecological significance.

In these ways, the Unfolded Shoreline serves as a "line" map and finds inspiration in the "stick maps" of the Marshall Islands (Figure 2), which are a fascinating example of simultaneously represented egocentric

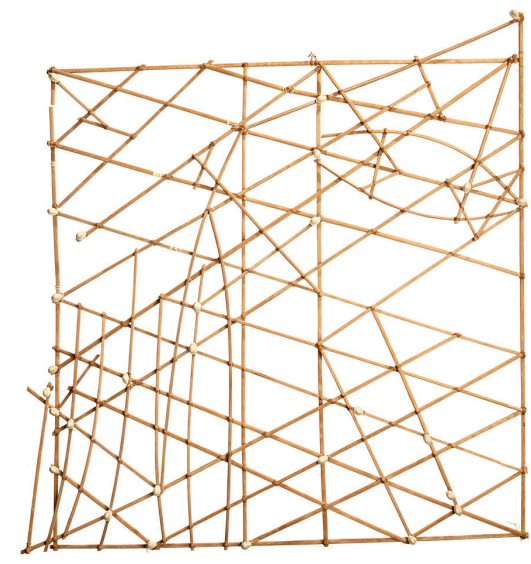

Figure 2: Stick Navigation Chart (Marshall Islands), Before 1950. Credit: Department of Anthropology, National Museum of Natural History, Smithsonian E432083 15 


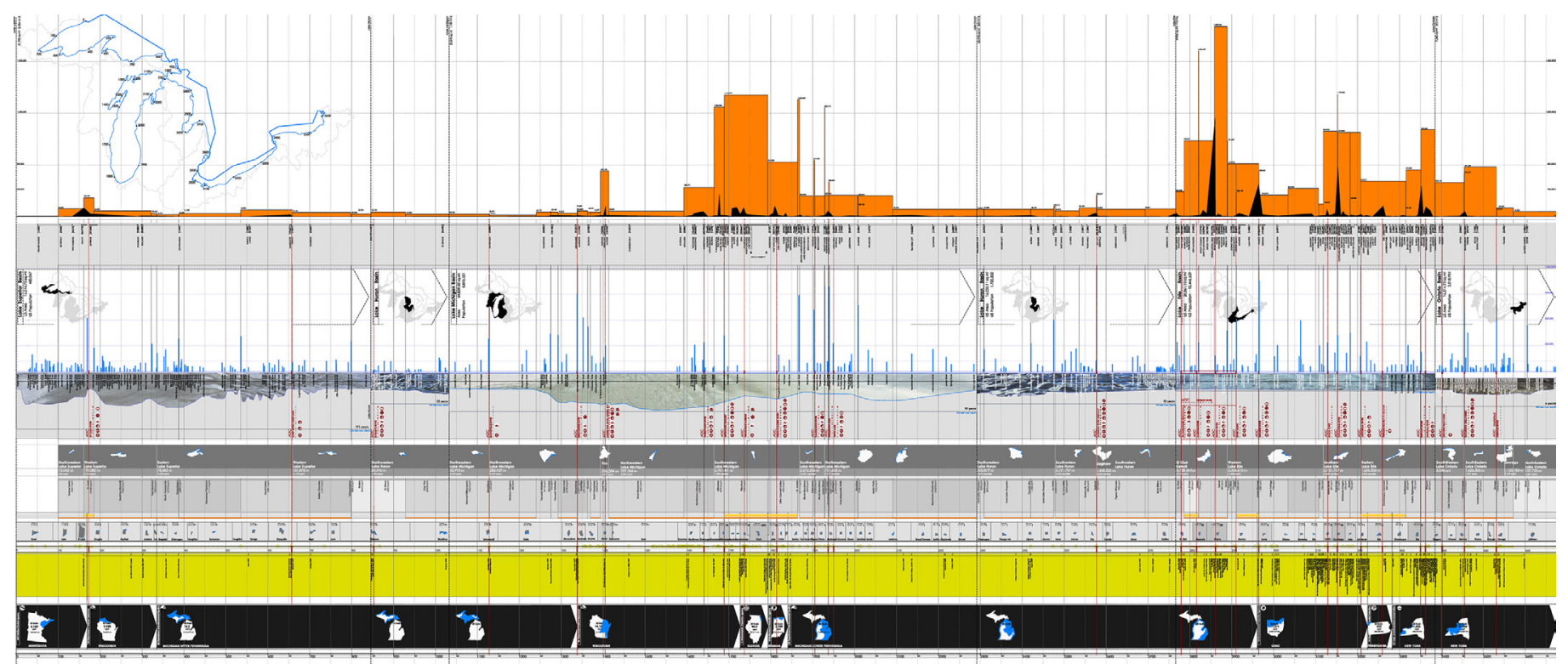

Figure 3: By "unfolding" the shorelands of the Great Lakes, specific feedback loops impacting urbanization of land and water and the related policies can be re-apprehended and ultimately guide integrated design responses. The displayed datasets include precise measurements of population, pollution, infrastructural components, political units, and other geographical elements.

(sensing) and allocentric (abstract) spatial information. ${ }^{17}$ In contradiction to previously upheld binary modalities of knowing (either cognitive or experiential), Marshallese navigators fluidly shift between cognition and experience when "wave running." 18,19 Within this context, the stick charts act as a didactic tool to teach and communicate both forms of knowing - the memory of cognitive information (e.g., the position of the islands) AND embodied sensory sources (e.g., what the patterns of wave refraction feel like when navigating a boat). In this way, it can be said that the abstraction of cartography becomes a tool to enliven perception.

Learning from the navigation of the cognitive and the projective, the unfolded drawing pulls a range of inter-dependent, yet politically and pragmatically isolated conditions together to didactically illustrate the unseen yet essential territory that must be navigated in order to address all the interdependent variables around water quality in the US Great Lakes Region.

\section{HYDROPHILIC HOOPHOUSE}

This project explores the possibility for the materialization of an environment as a site of typological transformation. Here, assumptions about "efficiency" are questioned and shifted from a default "economy of means" to the novel "economy of environment." Specifically, the collection of rainwater introduces new standards of performance expected from the assembly of an agricultural hoophouse.

Hoophouses have a long tradition of affordable and efficient assembly techniques that create micro-climates for extended season horticulture. Typically, this is accomplished with a series of parallel gabled, galvanized steel hoops wrapped with agricultural polypropylene and/or shade fabrics. While this standard approach is an effective model for capturing heat and light, it fails to address the third vital condition required by the growing plants: water.

The reorientation of hoops from parallel to interlaced effectively increases the capacity of the newly interconnected structural frame such that it can support water weight. Similarly, standard shade cloth is able to perform dual functions when moved to exterior of the structure and stretched to be taught, thereby enabling water to flow over the fabric. This is further calibrated with the addition of fabric pleats that direct the flow of water to specific collection points.

In both cases, the interplay between precise structural and fabric patterns accomplish a more inclusive environmental efficiency while also expressing these parameters in a perceptually dynamic way. Ultimately, the traditional hoophouse typology is revised through the environmental consideration of light, air and water performance, and is expressed through a common, yet rich material palette.

\section{PLAYFUL HORIZONS}

Playful Horizons offers a glimpse into the rich territories of "play" and "lines" as methodological provocateurs. The realm of play is so elusive that Victor Turner found it to be a compelling consideration in his work on liminality explicitly because it "occupies a threshold between reality and unreality, as if, for example, it were on the beach between the land and the sea". ${ }^{20}$ The act of play and the space of the horizon share similar conditions of indeterminacy and are often associated with attributes of openness, creativity and expanded imagination. To play is to engage in a universal experience that defies definition and engenders ambiguity. Across time and disciplines, scholars have often expressed their fascination with the aspects of play that are paradoxical and puzzling, such as qualities of ephemerality and mutability. 
Expanding on these ideas, Playful Horizons explores the material production of a grounded speculation that finds opportunity in the indeterminate aspects of play. The project traces and materializes "vectors" of play to produce a spatially bounded yet perceptually open "play-line." The three-dimensional "playlines" organize zones of play in relationship to a series of garden rooms "carved" out of a continuously changing landscape of textures, colors and fragrances. The geometric definition of the playline is constrained by a precise set of fabrication rules that guide its spatial articulation. While precise in relationship to the logics of CNC tube bending fabrication, it maintains a level of abstraction that inscribes a space of open-ended play to engage children's imagination. Subtle variations in tube diameter and geometric intricacy accommodate two, distinct age groups (infant through 2 years and 2 years through 5 years of age) within a shared and perceptually continuous play space. Hidden from perception but instrumental in negotiating safety, stringent regulations define the precise thickening and thinning of the ground to address uncertainty. In this way, play amplifies the physical and intellectual interplay between ground, line and sky.
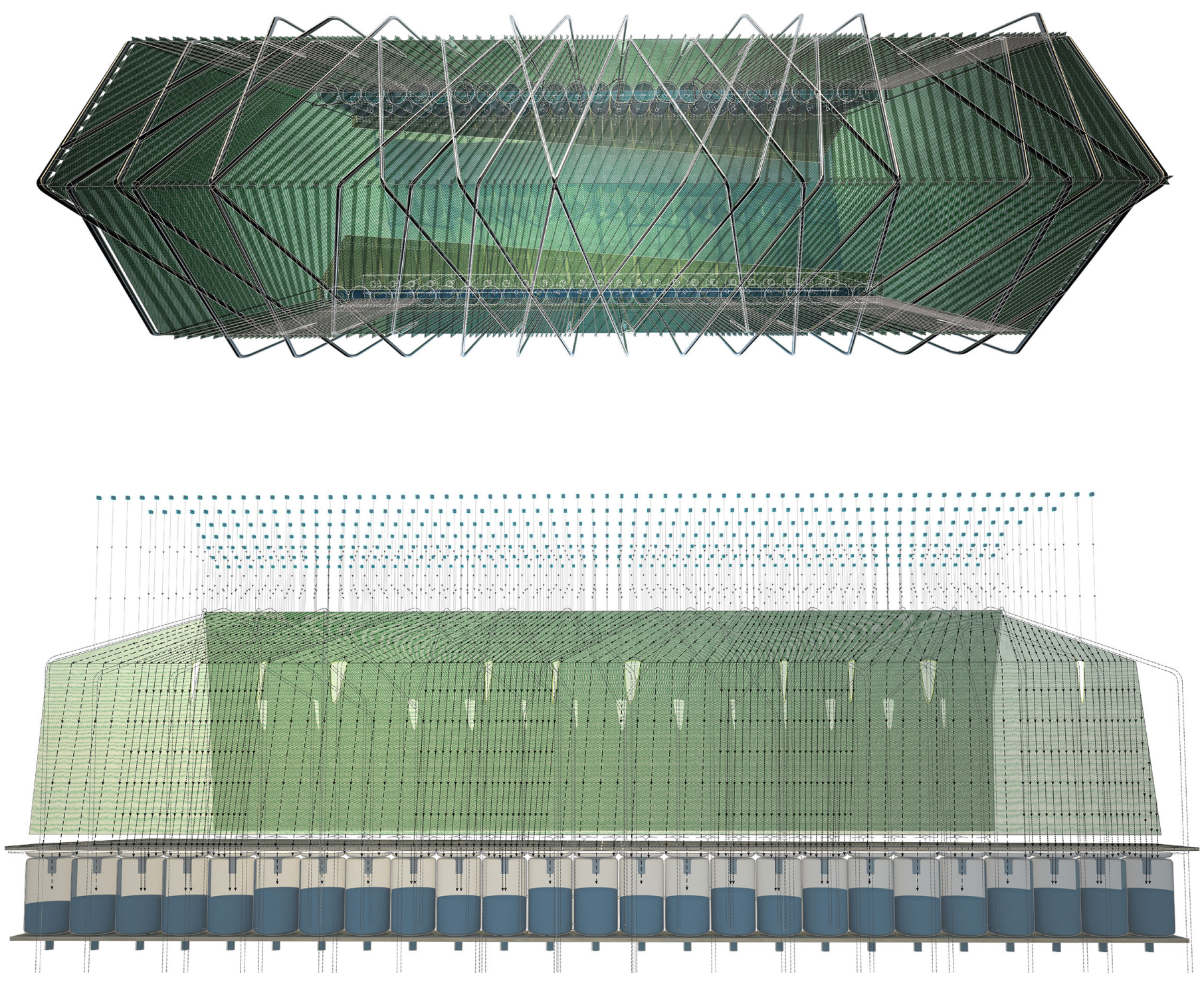

Figure 4: The gabled condition of the hoophouse sheds water quickly thereby enabling the use of shade cloth to also act as a water collector. Pleats in the shade cloth direct lines of water to containers below. The material performance of each piece in the prototypical assembly is key to its technical and perceptual transformation. 


\section{CONCLUSION}

Architecture is about world making. In continually reimagining the built environment, the discipline critically addresses global and local concerns. Today, quantitative measures of environmental phenomena and economic performance are veritably irrefutable and prioritized as fundamental to solving ecological and social crises. Rather than embracing a singular and narrow approach to design as problemsolving, this paper calls for a recalibration and expanded approach to generative design methods that encompass both precision and perception.

A close examination of the perception of dynamic, environmental systems (atmosphere) offers productive resistance to expectations for design precision (drawing) to describe and quantify these otherwise ephemeral conditions. In particular, recent scholarship on the consideration of "atmosphere" in architectural practice contextualizes the importance of linking individuals' daily experience of weather to broader, probabilistic predictions about climate. Similarly, a glimpse at the evolution of the definition of "disegno" reminds us that hand and mind, feeling and intellect have not always been conceptualized as mutually exclusive and needn't be thought of as such in the present and into the future. Instead, an openness to a range of practices that grow from the diversification of knowledge paradigms fosters design

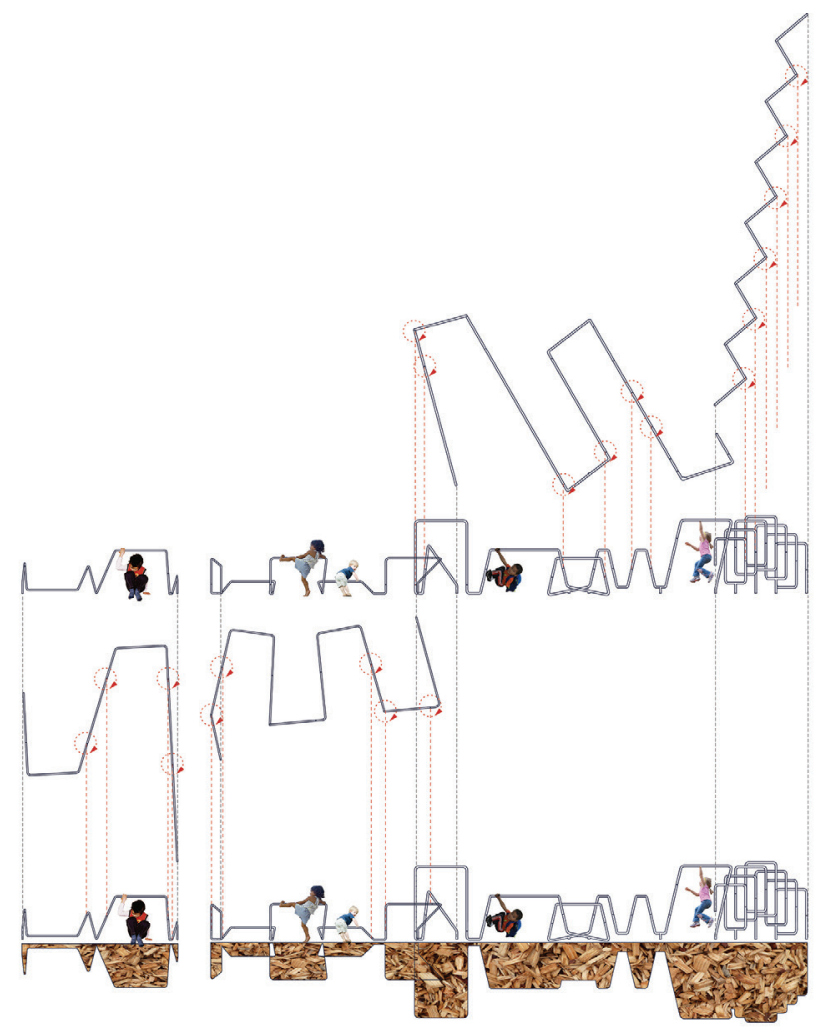

Figure 5: The activities that the line sponsors are only limited by imagination. Children can swing, twirl, slide, balance, jump, hang and invent new group games that interact with and around the lines. practices that revel in contingency and speculate on the temporal and material qualities that make architecture a thriving component of the dynamic, constructed world we share.

Similarly, glimpses of design projects illustrate the potential for small interventions to participate in disciplinary debates of contemporary attitudes toward "context" and environmental stewardship by fostering awareness through perception. Collectively, the playline, the hoophouse and the unfolded shoreline reveal opportunities for spatial invention, fabrication and the construction of cultural imagination.

\section{ENDNOTES}

1. Ruskin, John. 1904. The elements of drawing. London: G.Allen.

2. Herbertson, Andrew John. 1901. Outlines of Physiography: An Introduction to the Study of the Earth. London: Edward Arnold.

3. Hill, Jonathan. 2006. "Drawing Forth Immaterial Architecture." Architectural Research Quarterly 10(1): 51-55.

4. Dalston, Lorraine and Peter Galison. 1992. "The image of objectivity." Representations 40: 81-128.

5. Dalston, Lorraine and Peter Galison. 2007. Objectivity. New York: Zone Books

6. Jardine, Boris. 2014. "Made Real: Artifice and Accuracy in Nineteenth-Century Scientific Illustration." Science Museum Group Journal 2(2). doi:10.15180/140208

7. Jardine, Boris. 2014. "Made Real: Artifice and Accuracy in Nineteenth-Century Scientific Illustration." Science Museum Group Journal 2(2). doi:10.15180/140208.

8. Royal Meteorological Society/Science Museum / Science \& Society Picture Library. Image \#: 10452414, source \#: 1981-862|1981-862/29|10452414. accessed on July 20, 2016.

9. Klee, Paul. 1953. Pedagogical Sketchbook. New York: Praeger.

10. Hill, Jonathan. 2006. "Drawing Forth Immaterial Architecture." Architectural Research Quarterly 10(1): 51-55

11. Ajmar, Marta. 2014. "Mechanical Disegno." RIHA Journal 0084, Special Issue "When Art History Meets Design History." urn: urn:nbn:de:101:1-2014062622755, url:http://www.riha-journal.org/articles/2014/2014-jan-mar/special-issue-artdesign-history/ajmar-mechanical-disegno (date of access: April 4, 2106)

12. Banham, Reyner. 1990. "A Black Box: The Secret Profession of Architecture," New Statesman \& Society 3(122):22-25.

13. Ajmar, Marta. 2014. "Mechanical Disegno." RIHA Journal 0084, Special Issue "When Art History Meets Design History." urn: urn:nbn:de:101:1-2014062622755, url:http://www.riha-journal.org/articles/2014/2014-jan-mar/special-issue-artdesign-history/ajmar-mechanical-disegno (date of access: April 4, 2106)

14. Terzidis, Kostas. 2007. "The Etymology of Design: Pre-Socratic Perspective." Design Issues 23(4):69-78 doi:10.1162/desi.2007.23.4.69.

15. Hurlbert, Donald E. "E432083: Stick Navigation Chart" Smithosonian National Museum of Natural History, Department of Anthropology Collections, http://n2t. net/ark:/65665/3715cc0ec-8f02-44ba-8bd7-00371fae6ab9 (date of access: July 25, 2016).

16. Corner, James. 1999. "The Agency of Mapping: Speculation, Critique and Invention." Mappings Edited by Dennis E. Cosgrove. London:Reaktion Books.

17. Genz, Joseph. 2014. "Complementarity of Cognitive and Experiential Ways of Knowing the Ocean in Marshallese Navigation." Ethos, vol. 42, issue 3, pp. 332-351.

18. Kitchen, Rob and Mark Blades. 2002. The Cognition of Geographic Space. I.B. London: Taurus.

19. Genz, Joseph. 2014. "Complementarity of Cognitive and Experiential Ways of Knowing the Ocean in Marshallese Navigation." Ethos, vol. 42, issue 3, pp. 332-351.

20. Smith, Brian Sutton. 1997. The Ambiguity of Play. Cambridge, Mass: Harvard University Press. 